\title{
Erratum to "Investigating the Transferability of Calibrated Microsimulation Parameters for Operational Performance Analysis in Roundabouts"
}

\author{
Vincenzo Gallelli, Teresa Iuele, Rosolino Vaiana, and Alessandro Vitale \\ Department of Civil Engineering, University of Calabria, Rende, 87036 Cosenza, Italy \\ Correspondence should be addressed to Vincenzo Gallelli; vincenzo.gallelli@unical.it \\ Received 19 June 2017; Accepted 10 July 2017; Published 14 August 2017 \\ Copyright (c) 2017 Vincenzo Gallelli et al. This is an open access article distributed under the Creative Commons Attribution \\ License, which permits unrestricted use, distribution, and reproduction in any medium, provided the original work is properly \\ cited.
}

In the article titled "Investigating the Transferability of Calibrated Microsimulation Parameters for Operational Performance Analysis in Roundabouts" [1], there was an error in reference [17], which should be corrected as follows:

[17] R. Arroju, H. K. Gaddam, L. D. Vanumu, and K. Ramachandra Rao, "Comparative evaluation of roundabout capacities under heterogeneous traffic conditions," Journal of Modern Transportation, vol. 23, no. 4, pp. 310-324, 2015.

The reference has been corrected in the article.

\section{References}

[1] V. Gallelli, T. Iuele, R. Vaiana, and A. Vitale, "Investigating the transferability of calibrated microsimulation parameters for operational performance analysis in roundabouts," Journal of Advanced Transportation, vol. 2017, Article ID 3078063, 10 pages, 2017. 


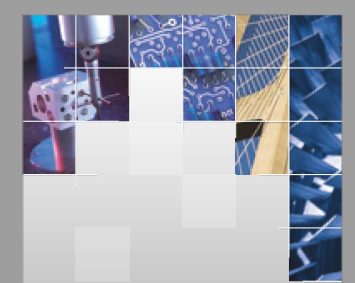

\section{Enfincering}
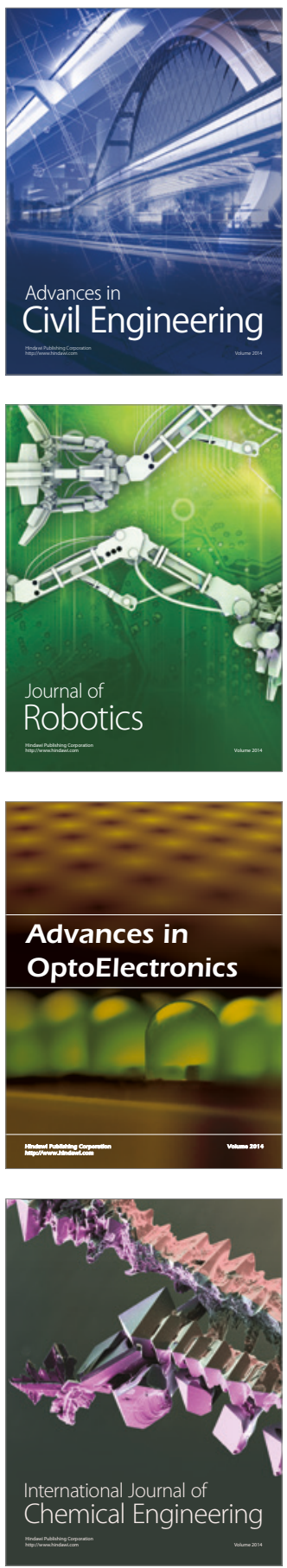

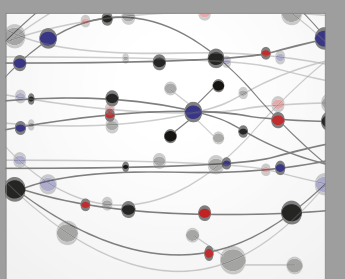

The Scientific World Journal

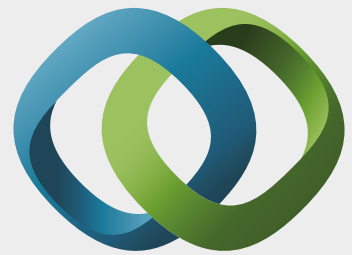

\section{Hindawi}

Submit your manuscripts at

https://www.hindawi.com
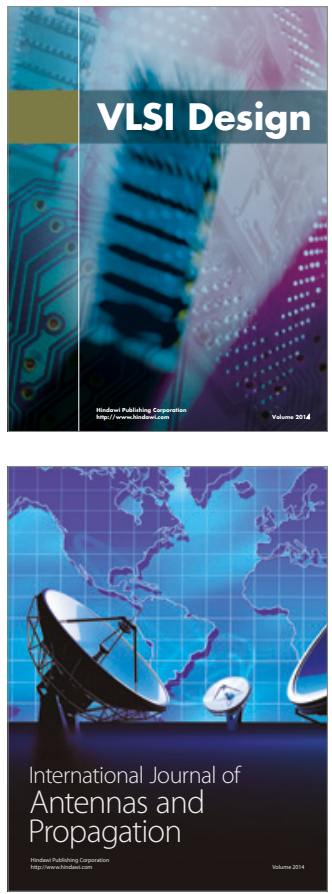

\section{Rotating}

Machinery
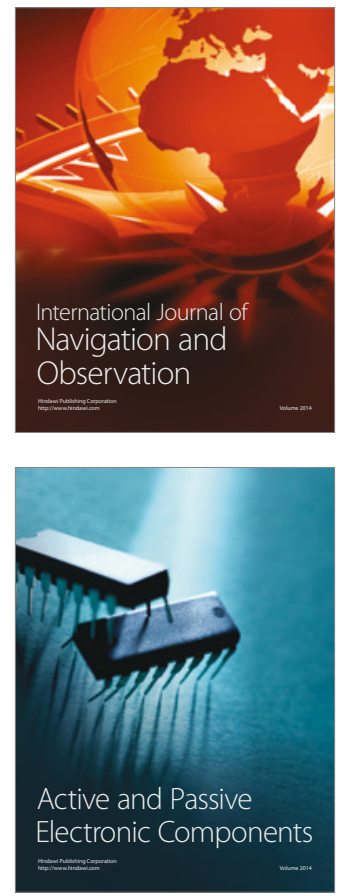
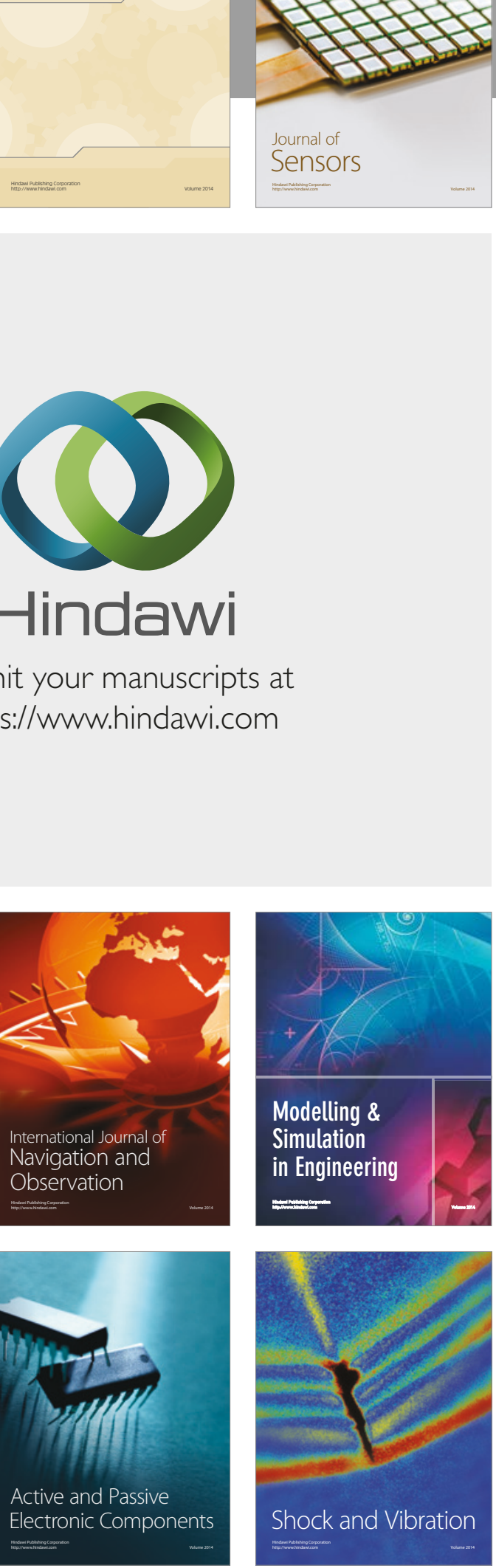
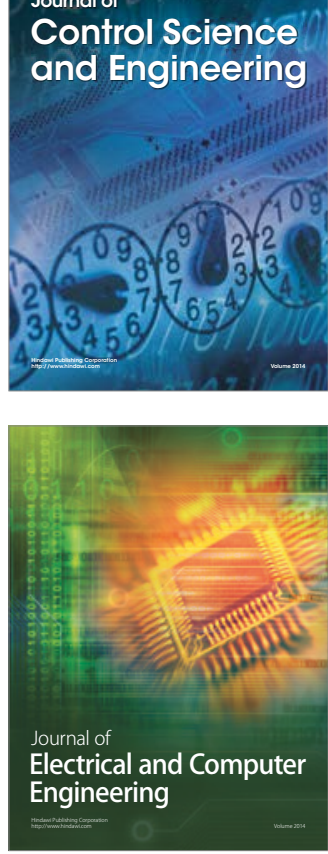

Distributed

Journal of

Control Science

and Engineering
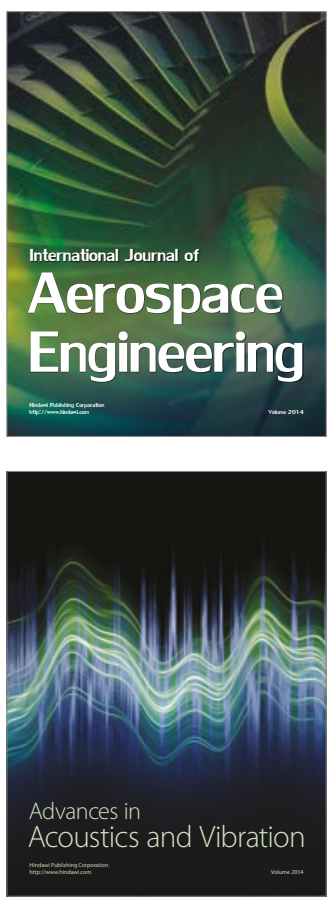

Sensor Networks 